\title{
Frequency of fruit and vegetable consumption and coronary heart disease in France and Northern Ireland: the PRIME study
}

\author{
Luc Dauchet $^{1}$, Jean Ferrières ${ }^{2}$, Dominique Arveiler ${ }^{3}$, John W. Yarnell ${ }^{4}$, Fred Gey ${ }^{5}$, Pierre Ducimetière ${ }^{6}$, \\ Jean-Bernard Ruidavets ${ }^{2}$, Bernadette Haas ${ }^{3}$, Alun Evans ${ }^{4}$, Annie Bingham ${ }^{6}$, Philippe Amouyel ${ }^{1}$ and \\ Jean Dallongeville ${ }^{1 *}$ \\ ${ }^{1}$ MONICA-Lille, INSERM U 508, Institut Pasteur de Lille, 1 rue du Prof Calmette, 59019 Lille Cedex, France \\ ${ }^{2}$ MONICA-Toulouse, INSERM U 558, Faculté de Médecine Purpan, Toulouse, France \\ ${ }^{3}$ MONICA-Strasbourg, Laboratoire d'Epidémiologie et de Santé Publique, Strasbourg, France \\ ${ }^{4}$ Belfast-MONICA, Department of Epidemiology and Public Health, Queen's University Belfast, Belfast, UK \\ ${ }^{5}$ The Vitamin Research Unit, The University of Bern, Switzerland \\ ${ }^{6}$ INSERM U 258, Hôpital Paul Brousse, Villejuif, France
}

(Received 15 April 2004 - Revised 17 August 2004 - Accepted 17 August 2004)

\begin{abstract}
Fruit and vegetable consumption is associated with low CHD risk in the USA and Northern Europe. There is, in contrast, little information about these associations in other regions of Europe. The goal of the present study was to assess the relationship between frequency of fruit and vegetable intake and CHD risk in two European populations with contrasting cardiovascular incidence rates; France and Northern Ireland. The present prospective study was in men aged 50-59 years, free of CHD, who were recruited in France $(n$ 5982) and Northern Ireland $(n$ 2105). Fruit and vegetable intake was assessed by a food-frequency questionnaire. Incident cases of acute coronary events and angina were recorded over a 5-year follow-up. During follow-up there was a total of 249 ischaemic events. After adjustment on education level, smoking, physical activity, alcohol consumption, employment status, BMI, blood pressure, serum total and HDL-cholesterol, the relative risks (RR) of acute coronary events were 0.67 (95\% CI 0.44, 1.03) and 0.64 (95\% CI 0.41, 0.99) in the 2nd and 3rd tertiles of citrus fruit consumption, respectively $(P$ for trend $<0.03)$. Similar results were observed in France and Northern Ireland. In contrast, the RR of acute coronary events for 'other fruit' consumption were $0.70(95 \%$ CI $0.31,1.56)$ and $0.52(95 \%$ CI $0.24,1 \cdot 14)$ respectively in Northern Ireland (trend $P<0.05)$ and $1.29(95 \%$ CI 0.69, 2.4) and $1.15(95 \%$ CI 0.68, 1.94) in France (trend $P=0.5$; interaction $P<0.04)$. There was no evidence for any association between vegetable intake and total CHD events. In conclusion, frequency of citrus fruit, but not other fruits, intake is associated with lower rates of acute coronary events in both France and Northern Ireland, suggesting that geographical or related factors might affect the relationship between fruit consumption and CHD risk.
\end{abstract}

Fruit: Vegetable: Coronary heart disease: Epidemiological cohort study

The consumption of nutrients from fruit and vegetables, such as dietary fibre, $\mathrm{K}$ and antioxidant vitamins, has been associated with a reduced risk of CVD in prospective studies (Khaw \& Barrett-Connor, 1987; Pietinen et al. 1996; Rimm et al. 1996; Iso et al. 1999; Marchioli et al. 2001). However, when the cardiovascular protective effect of some of these nutrients, for example antioxidant vitamins, was tested in clinical trials the results were at best non-significant (Marchioli et al. 2001). This has led the scientific community to shift its interest to the study of the cardioprotective properties of fruit and vegetables taken as a whole rather than a source of particular microor macronutrients.

In this respect, short-term clinical trials have shown that diets supplemented with fruit and vegetables are associated with a lowering of blood pressure and plasma cholesterol
(Jenkins et al. 1979, 1997; Robertson et al. 1979; StasseWolthuis et al. 1980; Tinker et al. 1991; Singh et al. 1992; Wisker et al. 1994; Appel et al. 1997). In addition, cohort studies have usually shown favourable trends between fruit and vegetable intake and the risk of IHD or stroke (Gaziano et al. 1995; Pietinen et al. 1996; Joshipura et al. 2001; Bazzano et al. 2002; Johnsen et al. 2003; Rissanen et al. 2003; Sauvaget et al. 2003) which are, at least in part, independent of classic cardiovascular risk factors. Finally, multifactorial intervention trials including increased fruit and vegetable consumption in survivors of myocardial infarction (MI) events have demonstrated major reductions in the recurrence of cardiac events despite modest changes in cardiovascular risk factors (Singh et al. 1993, 2002; Pietinen et al. 1996; de Lorgeril et al. 1999). This suggests that fruit and vegetables might affect 
cardiovascular risk through other factors than their effects on blood pressure and cholesterol levels.

When setting general dietary guidelines, the reproducibility of results across populations is an important factor to consider (Rimm, 2002). Yet, most data presented to date have been collected in North America or Northern Europe, two regions with elevated CHD rates (TunstallPedoe et al. 1999). In Italy, Greece and Spain, low intakes of fruit have been reported in survivors of MI enrolled in case-control studies (Martinez-Gonzalez et al. 2002; Negri et al. 2003; Panagiotakos et al. 2003). To our knowledge, there have been no reports of cohort studies in countries from Central and Southern Europe. Therefore, the goal of the present study was to assess the relationship between frequency of fruit and/or vegetables consumption and the CHD risk in France and Northern Ireland, two countries with contrasting CHD rates and different lifestyles.

\section{Methods \\ Population recruitment}

Cohort recruitment and examination methods have been described previously (Yarnell, 1998). Briefly, the Prospective Epidemiological Study of Myocardial Infarction (PRIME study) was established in 1991 in the populations of four WHO-MONICA centres in Belfast (UK), Lille, Strasbourg and Toulouse (France). The target was to recruit 2500 men, aged 50-59 years, in each centre and to follow them for a minimum of 5 years. The present paper was approved by the local ethics committee (Comité d'Ethique de l'Hôpital Broussais, séance no. 60 du 4 juin 1991, protocol no. 235) according to the regulation in France and Northern Ireland.

\section{Questionnaire}

Self-administered questionnaires related to demographic, socio-economic factors and diet were completed at home by the participants and checked with them by survey staff at the clinic. Data on educational level, occupational activity, personal and family history, tobacco and alcohol consumption, drug intake and physical activity were also collected. Physical activity was assessed for work and leisure times, on working days and at weekends. Subjects were classified into three categories: regular physical exercise (if they took intense physical activity more than $20 \mathrm{~min}$, once per week or more); moderate physical activity (light physical activity with no increased heart rate most weeks); no physical activity. Smoking habits were determined from questions on present and past habits, number and type of cigarettes, cigars or pipes smoked per d. Smokers were defined as individuals currently smoking at least one cigarette per d. Alcohol consumption was assessed by a questionnaire in which the subject reported his mean consumption (in units) of wine, beer, cider and spirits for each day of the week. Intake of alcohol was expressed in $\mathrm{ml}$ pure ethanol/week. Personal medical history of cardiovascular risk factors was assessed: the subject was first asked whether a medical doctor had ever reported a given risk factor, followed by a question on past and actual treatment. Diabetes was defined by a reported history of diabetes and current blood glucose-lowering therapy by dietary or pharmacological means. During an examination, the questionnaire on personal medical history was completed along with the London School of Hygiene Cardiovascular Questionnaire for Chest Pain on Effort and Possible Infarction (Rose et al. 1982), and a standard twelve-lead electrocardiogram was recorded. Of the initial 10600 subjects, 842 were excluded due to history of CHD. In addition, 1360 men who reported that they were on a diet for hypertension, hypercholesterolaemia or diabetes were excluded from the analyses. Finally, 312 were also excluded due to missing data on fruit and/or vegetable intake and/or adjustment variables, leaving a total of 8087 participants for study. Among the remaining patients, $106(1.3 \%)$ were lost to follow-up.

\section{Clinical examination}

The anthropometric measurements included height (to the nearest $\mathrm{cm}$ ), body weight (to the nearest $200 \mathrm{~g}$ ) with subjects in light clothing without their shoes. BMI was computed as weight $(\mathrm{kg})$ divided by height squared $\left(\mathrm{m}^{2}\right)$. Blood pressure was measured once at the end of the examination after a $5 \mathrm{~min}$ rest in the sitting position. Measurements were performed with an automatic device (Spengler SP9; Spengler, F94230 Cachan, France), which also recorded heart rate. A standard cuff size was used, but a large cuff was available when necessary. The devices were recalibrated every 3 months by the Co-ordinating Centre in Paris. Hypertension was defined by systolic blood pressure $\geq 140 \mathrm{mmHg}$ and/or diastolic blood pressure $\geq 90 \mathrm{mmHg}$ and/or current blood pressure-lowering treatment.

\section{Dietary assessment}

Dietary information on frequency of fruit and vegetable intake was obtained for four categories of fruit and vegetables ('citrus fruit', 'other fruit', 'raw vegetables' and 'baked vegetables'). Subjects were asked, through a personal interview at their home, to indicate their usual frequency of consumption of a standard portion of fruit or vegetables for the last weeks using the following scale: more than once per d (number per d); daily; three to four times per week; once per week; twice per month; once per month; never. Frequency of total 'fruit', 'vegetables' and 'fruit and vegetables' intake scores were calculated as the sum of number of servings per $d$ of fruit and/or vegetables. Potatoes were not included in the dietary scores because: (a) their vitamin and fibre composition is different from most other leafy vegetables; (b) their carbohydrate content is mostly of high glycaemic index; (c) in France, they are often eaten fried whereas in Northern Ireland they are boiled which adds to the complexity of the analysis. We did not validate the questionnaire against another dietary assessment method. However, a correlation analysis between the frequency of fruit and/or vegetable intake and plasma vitamins was performed in 100 men (twenty-five per centre, of which twenty were not analysed because the subjects were taking vitamin supplements) to assess 
the ability of the questionnaire to discriminate large $v$. small consumers of fruits and vegetables. Correlation analyses were performed between frequency of fruit and vegetable intake and plasma $\beta$-cryptoxanthin, vitamin $C, \alpha$-carotene, $\beta$-carotene and lutein (Zino et al. 1997; John et al. 2002).

\section{Blood sampling and assay procedures}

Venous blood was collected into siliconised vacutainer tubes (Vacutainer; Becton Dickinson, Franklin Lakes, NJ, USA) containing EDTA. Samples of plasma were immediately transferred to plastic tubes and frozen at $-80^{\circ} \mathrm{C}$. The frozen samples were then shipped in batches to the Central Laboratory in Lille. Plasma total cholesterol and HDLcholesterol levels were measured by enzymic methods using reagents from Boerhinger-Mannheim (Mannheim, Germany). LDL-cholesterol was calculated according to Friedewald's formula. Hypercholesterolaemia was defined by cholesterol levels $>2.4 \mathrm{~g} / 1$ or lipid-lowering treatment. The inter-assay CV for total cholesterol was $2 \%$. The liposoluble plasma vitamins were assayed by HPLC (Brubacher \& Vuilleumier, 1974) by the Swiss Reference Laboratory, Basel, Switzerland, appointed by the National Institute of Standards and Technology, Gaithersburgh, MD, USA. Vitamin C (sum of ascorbic and dehydroascorbic acid) was measured by automated fluorimetry (Brubacher \& Vuilleumier, 1974). The laboratory was blinded to the origin of the samples. The CV for all parameters was $\leq 3 \%$; periodic parallel analysis of reference samples controlled for systematic errors.

\section{Follow-up}

Briefly, subjects were contacted annually by letter and asked to complete a clinical event questionnaire to be returned to the centre in a pre-paid envelope. For all subjects reporting a possible event, clinical information was sought directly from the hospital or family doctor's notes. All details of electrocardiograms, hospital admissions, enzymes, surgical operations, angioplasty, treatment, etc. were collected. Death certificates were checked for supporting clinical and post-mortem information of cause of death. When necessary, the circumstances of death were obtained from the family doctor or the family. A medical committee was established, comprising one member from each PRIME centre and three independent cardiologists (two from France and one from the UK). Its task was to provide an independent validation of coronary events in the PRIME study. The committee met on four occasions during the 5-year follow-up period. All medical information, including all available electrocardiograms related to events, was sequentially displayed by each centre's representative and the committee assigned a code according to a strict protocol (Ducimetiere et al. 2001).

MI was defined as previously described (Ducimetiere et al. 2001). Definite coronary death was defined as death with documented coronary event. When significant coronary atheroma was present at autopsy, the death was considered as definite coronary death. When a coronary death was suspected, with no other documentation or explanation, it was labelled possible coronary death. The three death categories were grouped together as coronary death. Angina pectoris was defined by the presence of chest pain as extensively described (Ducimetiere et al. 2001). Unstable angina was defined as crescendo pain (change in frequency or severity of chest pain on exertion or appearance of chest pain at rest following pre-existing pain on exertion), with either enzyme changes or electrical changes. In the absence of enzyme or electrical data, the diagnosis was not upheld. Events were grouped in two categories, (1) acute events: MI and CHD death, (2) angina events: stable and unstable angina.

\section{Statistical analysis}

Baseline characteristics are presented by tertiles of frequency of fruit and vegetable intake. Linear trend (for continuous variables) and $\chi^{2}$ tests (for categorical variables) were used to compare values across tertiles. For trend analyses, fruit and vegetable intake was used as a continuous variable in the statistical model. Cox's proportional hazard regression models were used to assess the relationship between categories of frequency of fruit and vegetable intake and CHD. Adjustment variables were centre (four levels), education (three levels), smoking (current, never, former), physical activity (four levels), employment status (two levels), alcohol consumption (four levels) and age, BMI, blood pressure, total and HDL-cholesterol as continuous variables. Three different models were used: (1) adjusted on age and centre; (2) adjusted on age, centre and possible confounding variables (smoking, alcohol consumption, physical activity, educational level and employment status); (3) similar to second model plus explanatory variables (systolic blood pressure, total cholesterol, HDL-cholesterol, BMI, treatment for hypertension, diabetes or dyslipidaemia). These models gave similar results and thus only the results with the complete model are presented. An interaction test between country (France or Northern Ireland) and frequency of fruit and/ or vegetable intakes (as continuous variables) was performed. Whenever the interaction test was significant at $P<0 \cdot 10$, further analyses were performed in each country separately. The cut-off value of $P<0.05$ was used for statistical significance.

\section{Results}

Spearman's correlation coefficients between selected plasma vitamins and frequency of fruit and/or vegetable intake, assessed by the food-frequency questionnaire, were calculated in a sub-sample of eighty men. Frequency of fruit intake was correlated with $\beta$-cryptoxanthin $(r 0.32$; $P<0.005)$ and vitamin $\mathrm{C}(r 0.33 ; P<0.004)$. Frequency of citrus fruit intake was also correlated with $\beta$-cryptoxanthin ( $r$ 0.34; $P<0.002)$ and vitamin $C(r$ 0.37; $P<0.0007)$. Similarly, frequency of vegetable intake was correlated with $\alpha$-carotene $(r \quad 0.26 ; P<0.03), \beta$-carotene $(r \quad 0.29$; $P<0.02), \beta$-cryptoxanthin $(r 0.32 ; P<0.04)$ and vitamin $\mathrm{C}(r 0.24 ; P<0 \cdot 04)$.

Table 1 shows the frequency of fruit and/or vegetable intake and lifestyle characteristics of the participants in France and Northern Ireland. The frequency of fruit and vegetable intake was lower in Northern Ireland than in 
Table 1. Frequency of fruit and/or vegetable intake and lifestyle characteristics by country (Mean values and standard deviations or percentages)

\begin{tabular}{|c|c|c|c|c|c|}
\hline & \multicolumn{2}{|c|}{ France } & \multicolumn{2}{|c|}{ Northern Ireland } & \multirow[b]{2}{*}{$P^{*}$} \\
\hline & Mean & SD & Mean & SD & \\
\hline$n$ & \multicolumn{2}{|c|}{5982} & \multicolumn{2}{|c|}{2105} & \\
\hline $\begin{array}{l}\text { Fruit (frequency/d) } \\
\text { Q1-Q3 }\end{array}$ & \multicolumn{2}{|c|}{${ }_{0.5-2.0^{0.92}}^{1.18}$} & \multicolumn{2}{|c|}{$0.89-1.28^{0.8}$} & $<0.001$ \\
\hline $\begin{array}{l}\text { Vegetables (frequency/d) } \\
\text { Q1-Q3 }\end{array}$ & \multicolumn{2}{|c|}{$0.79-1.5$} & \multicolumn{2}{|c|}{$0.98 \quad 0.57-1.28^{0.78}$} & $<0.001$ \\
\hline $\begin{array}{l}\text { Fruit and vegetables (frequency/d) } \\
\text { Q1-Q3 }\end{array}$ & \multicolumn{2}{|c|}{$1.5-3.14$} & \multicolumn{2}{|c|}{$1.07-2.43$} & $<0.001$ \\
\hline Age (years) & $54 \cdot 8$ & $2 \cdot 9$ & $54 \cdot 7$ & $2 \cdot 9$ & $<0.08$ \\
\hline $\begin{array}{l}\text { Education level }(\%) \\
\text { Elementary school or less } \\
\text { High school } \\
\text { University }\end{array}$ & & & & & $<0.001$ \\
\hline Currently employed (\%) & \multicolumn{2}{|c|}{$78 \cdot 3$} & \multicolumn{2}{|c|}{$87 \cdot 6$} & $<0.001$ \\
\hline $\begin{array}{l}\text { Tobacco (\%) } \\
\text { Non-smoker } \\
\text { Ex-smoker } \\
\text { Current smoker }\end{array}$ & & & & & $<0.001$ \\
\hline $\begin{array}{l}\text { Physical activity (\%) } \\
\text { No } \\
\text { Light } \\
\text { Regular } \\
\text { Frequent }\end{array}$ & & & & & $<0.001$ \\
\hline $\begin{array}{l}\text { Alcohol consumption (\%) } \\
\text { Non-consumer } \\
\leq 171.1 \mathrm{ml} / \text { week } \\
171.1 \text { to } 374.1 \mathrm{ml} / \text { week } \\
\geq 374.1 \mathrm{ml} / \text { week }\end{array}$ & & & & & $<0.001$ \\
\hline Vitamin supplements ( $\% \geq 1 /$ week) & \multicolumn{2}{|c|}{$12 \cdot 7$} & \multicolumn{2}{|c|}{$20 \cdot 8$} & $<0.001$ \\
\hline
\end{tabular}

Q1-Q3, quartiles 1-3.

${ }^{*}$ The general linear procedure was used for continous variables and the $\chi^{2}$ test for categorical variables.

France. The level of education $(P<0 \cdot 001)$, of physical activity $(P<0.001)$ and of alcohol consumption $(P<0.001)$ was higher in France than in Northern Ireland. Inversely, the rate of men currently employed $(P<0.001)$, of smokers $(P<0.001)$ and of vitamin supplement consumers $(P<0.001)$ was lower in France than in Northern Ireland.

Table 2 shows the clinical, biological and lifestyle characteristics of men according to frequency of fruit and vegetable intake and country. In both France and Northern Ireland, men in the 3rd tertile of frequency of fruit and vegetable intake were more educated $(P<0.001)$, currently employed $(P<0.01)$, non-smokers $(P<0.001)$, physically active $(P<0.001)$, moderate alcohol consumers $(P<0.001)$ and users of vitamin supplements $(P<0.001)$ than men in the lowest tertile of the distribution. In France, BMI $(P=0.03)$, systolic blood pressure $(P<0.001)$ and total cholesterol were lower in the upper than in the lower tertile of fruit and vegetable distribution (data not shown). In Ireland, BMI was higher in men from the 3rd tertile than in the lower tertile $(P<0 \cdot 03)$.

Over the first 5 years of follow-up, 249 events occurred; 102 in Northern Ireland (incidence $1.0 \%$ per year) and 147 in France $(0.5 \%$ per year), including fifty-three acute events in Northern Ireland $(0.51 \%$ per year) and eighty in France $(0.27 \%$ per year). Three models were used to assess the relationship between frequency of fruit and vegetable intake and CHD: (1) adjusting for age and centre; (2) adjusting for age, centre and lifestyle variables; (3) a complete model adjusting for centre, age, smoking, alcohol consumption, physical activity, education level, employment status, systolic blood pressure, total cholesterol, HDL-cholesterol, BMI, treatment for hypertension, diabetes and dyslipidaemia. Since these analyses yielded similar results, only the results of the complete model are presented in Table 3. There was no evidence for a significant association between frequency of vegetable intake and acute coronary events or for an interaction between country. There was in contrast a significant association between citrus fruit intake and acute coronary events $(P<0.03)$ with a $36 \%$ lower risk (relative risk (RR) 0.64 $(95 \%$ CI $0.41,0.99)$ ) of incident acute coronary events in the upper tertile of citrus fruit distribution compared with the lower tertile. There was a statistically significant interaction between countries and frequency of 'other fruit' $(P<0.04)$, total fruit intake $(P<0.03)$ and frequency of fruit and vegetable intake $(P<0.07)$ on acute coronary event risk, thus suggesting a different association in France and Northern Ireland.

In order to investigate this interaction, further analyses were performed in both countries separately (Table 4). In Northern Ireland, other fruit $(P<0.05)$, total fruit $(P<0.01)$ and all fruit and vegetables $(P<0.02)$ were 
Fruits and vegetables and risk of CHD

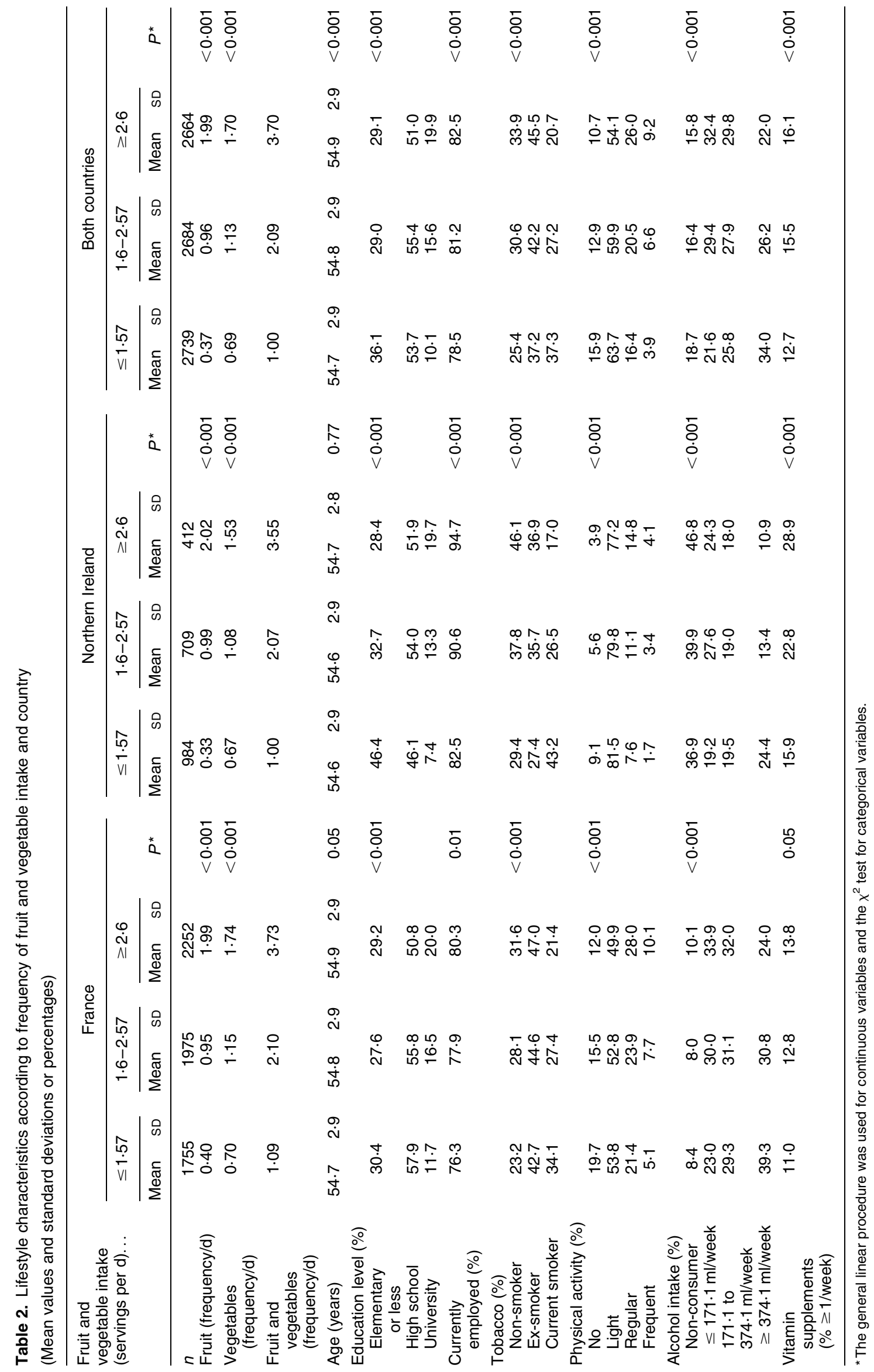


Table 3. Multivariate relative risk (RR) for acute coronary event in France and Northern Ireland according to frequency (Freq) of fruit and vegetable intake

\begin{tabular}{|c|c|c|c|c|c|c|}
\hline \multirow[b]{2}{*}{ Tertile... } & & \multicolumn{3}{|c|}{ France and Northern Ireland } & \multirow[b]{2}{*}{$P^{*}$} & \multirow[b]{2}{*}{$P \dagger$} \\
\hline & & 1 & 2 & 3 & & \\
\hline Raw vegetables & $\begin{array}{l}\text { Freq/d } \\
n \\
\text { Events } \\
\text { RR } \\
95 \% \mathrm{Cl}\end{array}$ & $\begin{array}{c}\leq 0.29 \\
3227 \\
68 \\
1 \\
-\end{array}$ & $\begin{array}{c}0.43-0.57 \\
2414 \\
27 \\
0.76 \\
0.46,1.23\end{array}$ & $\begin{array}{c}\geq 1 \\
2446 \\
38 \\
1 \cdot 17 \\
0 \cdot 71,1.91\end{array}$ & 0.44 & 0.45 \\
\hline Baked vegetables & $\begin{array}{l}\text { Freq/d } \\
n \\
\text { Events } \\
\text { RR } \\
95 \% \mathrm{Cl}\end{array}$ & $\begin{array}{c}\leq 0.29 \\
2465 \\
48 \\
1 \\
-\end{array}$ & $\begin{array}{c}0.43-0.57 \\
2916 \\
38 \\
0.69 \\
0.45,1.07\end{array}$ & $\begin{array}{c}\geq 1 \\
2706 \\
47 \\
0.93 \\
0.61,1.42\end{array}$ & 0.49 & 0.29 \\
\hline All vegetables & $\begin{array}{l}\text { Freq/d } \\
n \\
\text { Events } \\
\text { RR } \\
95 \% \mathrm{Cl}\end{array}$ & $\begin{array}{c}\leq 0.79 \\
3023 \\
57 \\
1 \\
-\end{array}$ & $\begin{array}{c}1-1.29 \\
2513 \\
37 \\
0.81 \\
0.54,1.23\end{array}$ & $\begin{array}{c}\geq 1.5 \\
2551 \\
39 \\
0.98 \\
0.82,1 \cdot 18\end{array}$ & 0.98 & 0.93 \\
\hline Citrus fruit & $\begin{array}{l}\text { Freq/d } \\
n \\
\text { Events } \\
\text { RR } \\
95 \% \mathrm{Cl}\end{array}$ & $\begin{array}{c}\leq 0.07 \\
2434 \\
59 \\
1 \\
-\end{array}$ & $\begin{array}{c}0.14-0.29 \\
2472 \\
35 \\
0.66 \\
0.44,1.03\end{array}$ & $\begin{array}{c}\geq 0.5 \\
3181 \\
39 \\
0.64 \\
0.41,0.99\end{array}$ & $<0.03$ & 0.63 \\
\hline Other fruit & $\begin{array}{l}\text { Freq/d } \\
n \\
\text { Events } \\
\text { RR } \\
95 \% \mathrm{Cl}\end{array}$ & $\begin{array}{c}\leq 0.29 \\
3253 \\
98 \\
1 \\
-\end{array}$ & $\begin{array}{c}0.43-0.57 \\
1582 \\
69 \\
0.99 \\
0.61,1.59\end{array}$ & $\begin{array}{c}\geq 1 \\
3252 \\
82 \\
0 \cdot 85 \\
0 \cdot 56,1 \cdot 29\end{array}$ & 0.61 & $<0.04$ \\
\hline All fruit & $\begin{array}{l}\text { Freq/d } \\
n \\
\text { Events } \\
\text { RR } \\
95 \% \mathrm{Cl}\end{array}$ & $\begin{array}{c}\leq 0.57 \\
2909 \\
64 \\
1 \\
-\end{array}$ & $\begin{array}{c}0.64-1 \cdot 14 \\
2322 \\
31 \\
0.68 \\
0.44,1.05\end{array}$ & $\begin{array}{c}\geq 1.29 \\
2856 \\
38 \\
0.74 \\
0.48,1.14\end{array}$ & $<0.05$ & $<0.03$ \\
\hline Fruit and vegetables & $\begin{array}{l}\text { Freq/d } \\
n \\
\text { Events } \\
\text { RR } \\
95 \% \mathrm{Cl}\end{array}$ & $\begin{array}{c}\leq 1.57 \\
2725 \\
68 \\
1 \\
-\end{array}$ & $\begin{array}{c}1.6-2.57 \\
2575 \\
26 \\
0.43 \\
0.27,0.69\end{array}$ & $\begin{array}{c}\geq 2 \cdot 60 \\
2787 \\
39 \\
0.75 \\
0.49,1 \cdot 15\end{array}$ & $<0.09$ & $<0.07$ \\
\hline
\end{tabular}

${ }^{*} P$ for trend. Adjustment on centre, age, smoking, alcohol consumption, physical activity, education level, employment status, systolic blood pressure, total cholesterol, HDL-cholesterol, BMI, treatment for hypertension, diabetes or dyslipidaemia.

$\dagger$ Interaction between frequency of consumption and country.

associated with a lower risk of acute coronary events. In France, there was no evidence for any statistically significant association between other fruit $(P<0 \cdot 50)$, total fruit $(P<0.57)$ and all fruit and vegetables $(P<0.60)$ and acute coronary events.

Finally, there was no evidence for any association between vegetable, fruit, and fruit and vegetable intake and total events (combined acute coronary events and angina) in France or in Northern Ireland or in both countries (Table 5). Although there was a tendency to lower total event rate across tertiles of citrus fruit intake (RR 0.77 (95\% CI 0.56, $1.05)$ and RR $0.76(95 \%$ CI $0.56,1.04))$ for the middle and upper tertile respectively), this reduction did not reach a level of statistical significance $(P$ trend $<0 \cdot 14)$.

\section{Discussion}

The objective of our work was to assess the relationship between the frequency of fruit and vegetable intake in two European countries at contrasting CHD risk and different lifestyles. The results showed a favourable association between the frequency of citrus fruit consumption and acute coronary events in France and Northern Ireland. In addition, other fruit intake was also associated with lower rates of acute coronary events in Northern Ireland but not in France, suggesting that geographical or related influences might affect the relationship between the consumption of fruits and CHD risk.

Few epidemiological studies have specifically analysed the effect of the consumption of citrus fruits on cardiovascular events. In the Nurses' Health Study and the Health Professionals' Follow-up Study, based on 126000 men and women, Joshipura et al. (2001) showed a reduction of $12 \%$ in the risk of $\mathrm{MI}$ in the top quintile of citrus fruit distribution as compared with the bottom quintile. Similarly, lower stroke rates were reported among consumers of citrus fruit in the USA (Joshipura et al. 1999) and Denmark (Johnsen et al. 2003). The present results 
Table 4. Multivariate relative risk (RR) for acute coronary events in France and Northern Ireland separately according to frequency (Freq) of fruit and fruit and vegetable intake

\begin{tabular}{|c|c|c|c|c|c|c|c|c|c|}
\hline \multirow[b]{2}{*}{ Tertile... } & & \multicolumn{3}{|c|}{ France } & \multirow[b]{2}{*}{$P^{*}$} & \multicolumn{3}{|c|}{ Northern Ireland } & \multirow[b]{2}{*}{$P^{*}$} \\
\hline & & 1 & 2 & 3 & & 1 & 2 & 3 & \\
\hline Citrus fruit & $\begin{array}{l}\text { Freq/d } \\
n \\
\text { Events } \\
\text { RR } \\
95 \% \mathrm{Cl}\end{array}$ & $\begin{array}{c}\leq 0.07 \\
1584 \\
26 \\
1 \\
-\end{array}$ & $\begin{array}{c}0.14-0.29 \\
1840 \\
23 \\
0.79 \\
0.45,1.39\end{array}$ & $\begin{array}{c}\geq 0.5 \\
2558 \\
31 \\
0.78 \\
0.45,1.34\end{array}$ & $<0 \cdot 11$ & $\begin{array}{c}\leq 0.07 \\
850 \\
33 \\
1 \\
-\end{array}$ & $\begin{array}{c}0.14-0.29 \\
632 \\
12 \\
0.59 \\
0.30,1 \cdot 15\end{array}$ & $\begin{array}{c}\geq 0.5 \\
623 \\
8 \\
0.43 \\
0.19,0.98\end{array}$ & $<0.16$ \\
\hline Other fruit & $\begin{array}{l}\text { Freq/day } \\
n \\
\text { Events } \\
\text { RR } \\
95 \% \mathrm{Cl}\end{array}$ & $\begin{array}{c}\leq 0.29 \\
2260 \\
28 \\
1 \\
-\end{array}$ & $\begin{array}{c}0.43-0.57 \\
1170 \\
17 \\
1.29 \\
0.69,2.4\end{array}$ & $\begin{array}{c}\geq 1 \\
2552 \\
35 \\
1 \cdot 15 \\
0 \cdot 68,1.94\end{array}$ & 0.50 & $\begin{array}{c}\leq 0.29 \\
993 \\
36 \\
1 \\
-\end{array}$ & $\begin{array}{c}0.43-0.57 \\
412 \\
8 \\
0.70 \\
0.31,1.56\end{array}$ & $\begin{array}{c}\geq 1 \\
700 \\
9 \\
0.52 \\
0.24,1 \cdot 14\end{array}$ & $<0.05$ \\
\hline All fruit & $\begin{array}{l}\text { Freq/d } \\
n \\
\text { Events } \\
\text { RR } \\
95 \% \mathrm{Cl}\end{array}$ & $\begin{array}{c}\leq 0.57 \\
1939 \\
26 \\
1 \\
-\end{array}$ & $\begin{array}{c}0.64-1 \cdot 14 \\
1722 \\
23 \\
1.00 \\
0.57,1.77\end{array}$ & $\begin{array}{c}\geq 1 \cdot 29 \\
2321 \\
31 \\
1.08 \\
0.62,1.87\end{array}$ & 0.57 & $\begin{array}{c}\leq 0.57 \\
970 \\
38 \\
1 \\
-\end{array}$ & $\begin{array}{c}0.64-1.14 \\
600 \\
8 \\
0.39 \\
0.18,0.85\end{array}$ & $\begin{array}{c}\geq 1.29 \\
535 \\
7 \\
0.39 \\
0.17,0.89\end{array}$ & $<0.01$ \\
\hline All fruit and vegetables & $\begin{array}{l}\text { Freq/d } \\
n \\
\text { Events } \\
\text { RR } \\
95 \% \mathrm{Cl}\end{array}$ & $\begin{array}{c}\leq 1.57 \\
1755 \\
31 \\
1 \\
-\end{array}$ & $\begin{array}{c}1.6-2.57 \\
1975 \\
17 \\
0.48 \\
0.27,0.87\end{array}$ & $\begin{array}{c}\geq 2.6 \\
2252 \\
32 \\
0.86 \\
0.51,1.44\end{array}$ & 0.60 & $\begin{array}{c}\leq 1.57 \\
970 \\
37 \\
1 \\
-\end{array}$ & $\begin{array}{c}1 \cdot 6-2 \cdot 57 \\
600 \\
9 \\
0.39 \\
0.18,0.80\end{array}$ & $\begin{array}{c}\geq 2.6 \\
535 \\
7 \\
0.56 \\
0.25,1.28\end{array}$ & $<0.02$ \\
\hline
\end{tabular}

${ }^{*} P$ for trend. Adjustment on centre, age, smoking, alcohol consumption, physical activity, education level, employment status, systolic blood pressure, total cholesterol, HDL-cholesterol, BMI, treatment for hypertension, diabetes or dyslipidaemia.

are in agreement with these findings and with previous studies which had shown a cardioprotective effect for dietary vitamin C (Marchioli et al. 2001). However, the latter associations were inconsistent across studies, suggesting that other factors than vitamin $\mathrm{C}$ might explain the beneficial effects of citrus fruit. Altogether, these results suggest that citrus fruit might have favourable effects on CHD prevention in countries at contrasting cardiovascular risk and different lifestyles.

The relationship between the frequency of fruit consumption and CHD risk in Northern Ireland is in agreement with findings in other cohorts from Northern Europe and the USA. In Finland, Pietinen et al. (1996) reported an RR for fatal MI of 0.60 (95\% CI $0.45,0.79)$ in subjects from the top quintile of fruit intake as compared with the bottom quintile. In Denmark, Johnsen et al. (2003) reported an RR for ischaemic stroke of 0.60 (95\% CI $0.38,0.95)$ in men and women from the top $v$. the bottom quintile of fruit consumption. Similarly, in the NHANES Follow-up Study in North America, the RR for CHD was 0.76 (95\% CI $0.56,1.03)$ in subjects consuming fruit and vegetables at least three times per $\mathrm{d}$ as compared with those who consumed them less that once per d (Bazzano et al. 2002). Finally, in the Nurses' Health Study and the Health Professionals' Follow-up Study, subjects in the highest quintile of fruits had an RR for CHD of 0.80 (95\% CI $0.69,0.92$ ) compared with those in the lowest quintile (Joshipura et al. 2001). In the present study, although a significant trend was found between acute coronary event risk and frequency of fruit consumption in Northern Ireland, there was no visual evidence of a continuous decreasing gradient of risk across categories of frequencies of fruit intake; the risk was already minimum (RR 0.39) in the second tertile of frequency. One possible explanation to this finding is that a dose effect is not detectable due to the small number of events and large variability. Thus, it appears that in countries with high rates of cardiovascular mortality, such as the USA, Northern Europe and Northern Ireland (Tunstall-Pedoe et al. 1999), fruit consumption is associated with a reduction in CHD morbidity and mortality.

The association between fruit intake and cardiovascular events differed in Northern Ireland and France; the association was favourable in Northern Ireland but not in France. A similar interaction, although not statistically significant, was reported (Bazzano et al. 2002; Rimm, 2002) in the NHANES Survey Follow-up Study. In this survey, vegetable and fruit intake was associated with a reduction in coronary risk in white Americans, but not in non-white. In contrast, Steffen et al. (2003) found a stronger association between fruit and vegetable intake and the risk of incident coronary artery disease among African-Americans than among caucasians $(P=0.01$ for interaction). Altogether, these data suggest that the relationship between fruit intake and CHD risk could vary across different geographical areas, ethnic groups and/or according to the type of fruit consumed. There are several possible explanations for this interaction. Firstly, the fruit that are usually consumed by men in Northern Ireland might be different from those consumed in France and these differences might be associated with specific protective effects in Northern Ireland. This hypothesis is supported by the analysis of the food-standardised balance sheets. The supply per capita of bananas and apples is large in Ireland, whereas fruit supplies are more diverse in France (Food and Agriculture Organization, 2003). However, this hypothesis also implies that the fruit consumed in Northern Ireland have protective effects, whereas those consumed in 
Table 5. Multivariate relative risk (RR) for total coronary events in France and Northern Ireland according to frequency (Freq) of fruit and/or vegetable intake

\begin{tabular}{|c|c|c|c|c|c|c|}
\hline \multirow[b]{2}{*}{ Tertile... } & & \multicolumn{3}{|c|}{ France and Northern Ireland } & \multirow[b]{2}{*}{$P^{*}$} & \multirow[b]{2}{*}{$P \dagger$} \\
\hline & & 1 & 2 & 3 & & \\
\hline Raw vegetables & $\begin{array}{l}\text { Freq/d } \\
n \\
\text { Events } \\
\text { RR } \\
95 \% \mathrm{Cl}\end{array}$ & $\begin{array}{c}\leq 0.29 \\
3227 \\
118 \\
1 \\
-\end{array}$ & $\begin{array}{c}0.43-0.57 \\
2414 \\
67 \\
1.08 \\
0.77,1.51\end{array}$ & $\begin{array}{c}\geq 1 \\
2446 \\
64 \\
1 \cdot 19 \\
0 \cdot 82,1 \cdot 72\end{array}$ & 0.59 & 0.92 \\
\hline Baked vegetables & $\begin{array}{l}\text { Freq/d } \\
n \\
\text { Events } \\
\text { RR } \\
95 \% \mathrm{Cl}\end{array}$ & $\begin{array}{c}\leq 0.29 \\
2465 \\
77 \\
1 \\
-\end{array}$ & $\begin{array}{c}0.43-0.57 \\
2916 \\
90 \\
0.96 \\
0.71,1.30\end{array}$ & $\begin{array}{c}\geq 1 \\
2706 \\
82 \\
0 \cdot 98 \\
0 \cdot 72,1 \cdot 34\end{array}$ & 0.54 & 0.54 \\
\hline All vegetables & $\begin{array}{l}\text { Freq/d } \\
n \\
\text { Events } \\
\text { RR } \\
95 \% \mathrm{Cl}\end{array}$ & $\begin{array}{c}\leq 0.79 \\
3023 \\
107 \\
1 \\
-\end{array}$ & $\begin{array}{c}1-1.29 \\
2513 \\
73 \\
0.84 \\
0.63,1 \cdot 13\end{array}$ & $\begin{array}{c}\geq 1.5 \\
2551 \\
69 \\
1.01 \\
0.88,1 \cdot 15\end{array}$ & 0.93 & 0.66 \\
\hline Citrus fruit & $\begin{array}{l}\text { Freq/d } \\
n \\
\text { Events } \\
\text { RR } \\
95 \% \mathrm{Cl}\end{array}$ & $\begin{array}{c}\leq 0.07 \\
2434 \\
98 \\
1 \\
-\end{array}$ & $\begin{array}{c}0.14-0.29 \\
2472 \\
69 \\
0.77 \\
0.56,1.05\end{array}$ & $\begin{array}{c}\geq 0.5 \\
3181 \\
82 \\
0.76 \\
0.56,1.04\end{array}$ & 0.14 & 0.33 \\
\hline Other fruit & $\begin{array}{l}\text { Freq/d } \\
n \\
\text { Events } \\
\text { RR } \\
95 \% \mathrm{Cl}\end{array}$ & $\begin{array}{c}\leq 0.29 \\
3253 \\
112 \\
1 \\
-\end{array}$ & $\begin{array}{c}0.43-0.57 \\
1582 \\
47 \\
0.98 \\
0.68,1.39\end{array}$ & $\begin{array}{c}\geq 1 \\
3252 \\
90 \\
0 \cdot 96 \\
0 \cdot 71,1 \cdot 30\end{array}$ & 0.58 & 0.56 \\
\hline All fruit & $\begin{array}{l}\text { Freq/d } \\
n \\
\text { Events } \\
\text { RR } \\
95 \% \mathrm{Cl}\end{array}$ & $\begin{array}{c}\leq 0.57 \\
2909 \\
108 \\
1 \\
-\end{array}$ & $\begin{array}{c}0.64-1.14 \\
2322 \\
63 \\
0.83 \\
0.60,1.14\end{array}$ & $\begin{array}{c}\geq 1.29 \\
2856 \\
78 \\
0.90 \\
0.66,1.24\end{array}$ & $0 \cdot 13$ & 0.22 \\
\hline All fruit and vegetables & $\begin{array}{l}\text { Freq/d } \\
n \\
\text { Events } \\
\text { RR } \\
95 \% \mathrm{Cl}\end{array}$ & $\begin{array}{c}\leq 1.57 \\
2739 \\
118 \\
1 \\
-\end{array}$ & $\begin{array}{c}1 \cdot 6-2 \cdot 57 \\
2684 \\
62 \\
0 \cdot 61 \\
0.45,0.83\end{array}$ & $\begin{array}{c}\geq 2.60 \\
2664 \\
69 \\
0.78 \\
0.56,1.07\end{array}$ & $0 \cdot 18$ & 0.18 \\
\hline
\end{tabular}

${ }^{\star} P$ for trend. Adjustment on centre, age, smoking, alcohol consumption, physical activity, education level, employment status, systolic blood pressure, total cholesterol, HDL-cholesterol, BMI, treatment for hypertension, diabetes or dyslipidaemia. $\dagger$ Interaction between frequency of consumption and country.

France are less protective, an assumption which lacks plausibility. Secondly, it is possible that the beneficial effect of fruit is limited to countries with unhealthy dietary habits, and is less pronounced in countries where diets are healthier. Unhealthy dietary patterns are associated with unfavourable risk factor profiles that may be partly corrected by fruit consumption. In agreement with this hypothesis, men in Northern Ireland consumed more fats and saturated fatty acids than French men (Evans et al. 1995; Kelleher et al. 2002), had a poorer cardiovascular risk profile (Yarnell, 1998) and low levels of plasma vitamins (Evans et al. 1995). Therefore the substitution of food items with fruit and vegetables could theoretically be favourable in Northern Ireland and neutral in France, explaining the lack of a significant relationship in France. Moreover, if part of the protective effect of fruits depends on their vitamin content, it is likely that men in Northern Ireland will benefit more from the consumption of fruit than men in France. Lastly, this result might possibly be related to a residual effect of unmeasured confounders which could be more pronounced in Northern Ireland than in France. Since fruit availability is less important and fruit retail prices are higher in Northern Ireland than in France, the frequent consumption of fruit might reflect a great interest for healthy behaviours in Northern Ireland resulting in fewer cardiovascular events.

In the PRIME study there was no significant relationship between cardiovascular risk and vegetable intake. Similarly, in Southern Europe, case-control studies have found favourable relationships between the risk of MI and fruit but not with vegetable intake (Sasazuki, 2001; Martinez-Gonzalez et al. 2002; Negri et al. 2003). In contrast, Joshipura et al. (2001) and Pietinen et al. (1996) reported lower coronary risk among vegetable consumers in the USA and Finland, respectively. However, the relatively limited number of events in the present study, in particular in the analysis by country, does not allow us to rule out modest associations between vegetable consumption and coronary risk. Finally, the relationship between fruit and risk was limited to acute coronary events, but not 
angina - and total events -, suggesting a specific effect of fruits on acute events. However, an alternative hypothesis could be that angina and total events make up a heterogeneous group of events, with different pathophysiological background, which creates variability in the data resulting in non-significant results. Therefore, large numbers of events are necessary to confirm these findings.

The present study has a number of limitations. Firstly, the relatively low number of events limits the statistical power of the analyses and allows us to detect only major associations. Secondly, the food-frequency questionnaire is too simple a tool to quantitatively assess food intake. For instance, although a correlation between the frequency of fruit or vegetable consumption and the amount consumed daily is theoretically possible, an alternate possibility is that frequent consumers reduce their portion size. The latter hypothesis would tend to reduce the ability to find a significant effect, if any. Therefore, the results of the present study should be understood as an analysis of the relationship concerning the frequency, rather than with the amount, of fruit or vegetable intake. In this respect, Thompson et al. (2002) showed that questionnaires with a restricted number of items and without quantitative assessment of portion size do not affect the ability to rank subjects according to fruit or vegetable intake very much. Moreover, the correlation analysis between frequency of fruit or vegetable intake and plasma vitamin levels observed in the present study suggests that frequency of fruit and vegetable intake assessment was reasonably accurate. For instance, Bingham et al. (1997) found correlation values of $0.34,0.31,0.21$ and 0.48 between vitamin intake assessed with a reference method and plasma $\alpha$-carotene, $\beta$-carotene, $\beta$-cryptoxanthin and vitamin $C$ respectively. In addition, food intake was assessed only at entry to the present study. Therefore, changes in dietary habit over time could have weakened the strength of the associations. However, Goldbohm et al. (1995) showed in a cohort of Dutch men aged 55 to 68 years that food habits were stable over 5 years, arguing in favour of stability in the dietary practices of men of this age. Lastly, since the food-frequency questionnaire had a limited number of items, it was not possible to adjust for other nutritional factors such as total energy intake, saturated and polyunsaturated fats. Therefore, part of the observed associations between fruit and/or vegetables might be explained by compensatory changes in other nutrients or food items.

In conclusion, the results of the PRIME study show a favourable relationship between the frequency of citrus fruit consumption and the risk of acute coronary events in France and Northern Ireland. In contrast, the association between the consumption of other fruit and risk was observed only in Northern Ireland. Altogether, the present results, together with earlier reports, support the concept that citrus fruit are cardioprotective in populations from Europe and North America. It also suggests that geographical or related influences might affect the relationship between fruit intake and CHD risk. Further studies comparing the possible protective effect of fruit and vegetable intake in Southern Europe are necessary to confirm these results.

\section{Acknowledgements}

We thank the following organisations which allowed the recruitment of the PRIME subjects: the health-screening centres organised by the Social Security of Lille (Institut Pasteur), Strasbourg, Toulouse and Tourcoing; Occupational Medicine Services of Haute-Garonne, of the Urban Community of Strasbourg; the Association Inter-entreprises des Services Médicaux du Travail de Lille et environs; the Comité pour le Développement de la Médecine du Travail; the Mutuelle Générale des PTT du Bas-Rhin; the Laboratoire d'Analyses de l'Institut de Chimie Biologique de la Faculté de Médecine de Strasbourg; the Department of Health (NI) and the Northern Ireland Chest Heart and Stroke Association. There are no conflicts of interest to declare. The PRIME study was supported by grants from INSERM, Pasteur Institute and the Merck, Sharp and Dohme-Chibret Laboratory.

\section{References}

Appel LJ, Moore TJ, Obarzanek E, et al. (1997) A clinical trial of the effects of dietary patterns on blood pressure. DASH Collaborative Research Group. N Engl J Med 336, 1117-1124.

Bazzano LA, He J, Ogden LG, Loria CM, Vupputuri S, Myers L $\&$ Whelton PK (2002) Fruit and vegetable intake and risk of cardiovascular disease in US adults: the first National Health and Nutrition Examination Survey Epidemiologic Follow-up Study. Am J Clin Nutr 76, 93-99.

Bingham SA, Gill C, Welch A, et al. (1997) Validation of dietary assessment methods in the UK arm of EPIC using weighed records, and 24-hour urinary nitrogen and potassium and serum vitamin $\mathrm{C}$ and carotenoids as biomarkers. Int J Epidemiol 26, Suppl. 1, S137-S151.

Brubacher G \& Vuilleumier J (1974) Procedure for determination of vitamin $\mathrm{C}$ in plasma. In Clinical Biochemistry: Principles and Methods, pp. 992-997 [HCH Curtius and M Roth, editors]. Berlin: Walter de Gruyter.

de Lorgeril M, Salen P, Martin JL, Monjaud I, Delaye J \& Mamelle N (1999) Mediterranean diet, traditional risk factors, and the rate of cardiovascular complications after myocardial infarction: final report of the Lyon Diet Heart Study. Circulation 99, 779-785.

Ducimetiere P, Ruidavets JB, Montaye M, Haas B \& Yarnell J (2001) Five-year incidence of angina pectoris and other forms of coronary heart disease in healthy men aged 50-59 in France and Northern Ireland: the Prospective Epidemiological Study of Myocardial Infarction (PRIME) Study. Int J Epidemiol 30, 1057-1062.

Evans AE, Ruidavets JB, McCrum EE, et al. (1995) Autres pays, autres coeurs? Dietary patterns, risk factors and ischaemic heart disease in Belfast and Toulouse. QJM 88, 469-477.

Food and Agriculture Organization (2003) Food Standardized Balance Sheet. Rome: FAO.

Gaziano JM, Manson JE, Branch LG, Colditz GA, Willett WC \& Buring JE (1995) A prospective study of consumption of carotenoids in fruits and vegetables and decreased cardiovascular mortality in the elderly. Ann Epidemiol 5, 255-260.

Goldbohm RA, van't Veer P, van den Brandt PA, van't Hof MA, Brants HA, Sturmans F \& Hermus RJ (1995) Reproducibility of a food frequency questionnaire and stability of dietary habits determined from five annually repeated measurements. Eur J Clin Nutr 49, 420-429.

Iso H, Stampfer MJ, Manson JE, Rexrode K, Hennekens CH, Colditz GA, Speizer FE \& Willett WC (1999) Prospective 
study of calcium, potassium, and magnesium intake and risk of stroke in women. Stroke 30, 1772-1779.

Jenkins DJ, Popovich DG, Kendall CW, et al. (1997) Effect of a diet high in vegetables, fruit, and nuts on serum lipids. Metabolism 46, 530-537.

Jenkins DJ, Reynolds D, Leeds AR, Waller AL \& Cummings JH (1979) Hypocholesterolemic action of dietary fiber unrelated to faecal bulking effect. Am J Clin Nutr 32, 2430-2435.

John JH, Ziebland S, Yudkin P, Roe LS \& Neil HA (2002) Effects of fruit and vegetable consumption on plasma antioxidant concentrations and blood pressure: a randomised controlled trial. Lancet 359, 1969-1974.

Johnsen SP, Overvad K, Stripp C, Tjonneland A, Husted SE \& Sorensen HT (2003) Intake of fruit and vegetables and the risk of ischemic stroke in a cohort of Danish men and women. Am J Clin Nutr 78, 57-64.

Joshipura KJ, Ascherio A, Manson JE, Stampfer MJ, Rimm EB, Speizer FE, Hennekens CH, Spiegelman D \& Willett WC (1999) Fruit and vegetable intake in relation to risk of ischemic stroke. JAMA 282, 1233-1239.

Joshipura KJ, Hu FB, Manson JE, et al. (2001) The effect of fruit and vegetable intake on risk for coronary heart disease. Ann Intern Med 134, 1106-1114.

Kelleher C, Friel S, Nolan G \& Forbes B (2002) Effect of social variation on the Irish diet. Proc Nutr Soc 61, 527-536.

Khaw KT \& Barrett-Connor E (1987) Dietary potassium and stroke-associated mortality. A 12-year prospective population study. N Engl J Med 316, 235-240.

Marchioli R, Schweiger C, Levantesi G, Tavazzi L \& Valagussa F (2001) Antioxidant vitamins and prevention of cardiovascular disease: epidemiological and clinical trial data. Lipids 36, Suppl., S53-S63.

Martinez-Gonzalez MA, Fernandez-Jarne E, Martinez-Losa E, Prado-Santamaria M, Brugarolas-Brufau C \& Serrano-Martinez M (2002) Role of fibre and fruit in the Mediterranean diet to protect against myocardial infarction: a case-control study in Spain. Eur J Clin Nutr 56, 715-722.

Negri E, La Vecchia C, Pelucchi C, Bertuzzi M \& Tavani A (2003) Fiber intake and risk of nonfatal acute myocardial infarction. Eur J Clin Nutr 57, 464-470.

Panagiotakos DB, Pitsavos C, Kokkinos P, Chrysohoou C, Vavuranakis M, Stefanadis C \& Toutouzas P (2003) Consumption of fruits and vegetables in relation to the risk of developing acute coronary syndromes; the CARDIO2000 case-control study. Nutr J 2, 2.

Pietinen P, Rimm EB, Korhonen P, Hartman AM, Willett WC, Albanes D \& Virtamo J (1996) Intake of dietary fiber and risk of coronary heart disease in a cohort of Finnish men. The Alpha-Tocopherol, Beta-Carotene Cancer Prevention Study. Circulation 94, 2720-2727.

Rimm EB (2002) Fruit and vegetables - building a solid foundation. Am J Clin Nutr 76, 1-2.

Rimm EB, Ascherio A, Giovannucci E, Spiegelman D, Stampfer MJ \& Willett WC (1996) Vegetable, fruit, and cereal fiber intake and risk of coronary heart disease among men. JAMA 275, 447-451.

Rissanen TH, Voutilainen S, Virtanen JK, Venho B, Vanharanta M, Mursu J \& Salonen JT (2003) Low intake of fruits, berries and vegetables is associated with excess mortality in men: the Kuopio Ischaemic Heart Disease Risk Factor (KIHD) Study. J Nutr 133, 199-204.

Robertson J, Brydon WG, Tadesse K, Wenham P, Walls A \& Eastwood MA (1979) The effect of raw carrot on serum lipids and colon function. Am J Clin Nutr 32, 1889-1892.
Rose G, Blackburn H, Gillum R \& Prineas R (1982) Cardiovascular Survey Methods. WHO monograph series, 2nd edn. Washington, DC: WHO.

Sasazuki S (2001) Case-control study of nonfatal myocardial infarction in relation to selected foods in Japanese men and women. Jpn Circ J 65, 200-206.

Sauvaget C, Nagano J, Allen N \& Kodama K (2003) Vegetable and fruit intake and stroke mortality in the Hiroshima/Nagasaki Life Span Study. Stroke 34, 2355-2360.

Singh RB, Dubnov G, Niaz MA, Ghosh S, Singh R, Rastogi SS, Manor O, Pella D \& Berry EM (2002) Effect of an IndoMediterranean diet on progression of coronary artery disease in high risk patients (Indo-Mediterranean Diet Heart Study): a randomised single-blind trial. Lancet 360, $1455-1461$

Singh RB, Niaz MA, Ghosh S, Singh R \& Rastogi SS (1993) Effect on mortality and reinfarction of adding fruits and vegetables to a prudent diet in the Indian experiment of infarct survival (IEIS). J Am Coll Nutr 12, 255-261.

Singh RB, Rastogi SS, Singh R, Ghosh S \& Niaz MA (1992) Effects of guava intake on serum total and high-density lipoprotein cholesterol levels and on systemic blood pressure. Am J Cardiol 70, 1287-1291.

Stasse-Wolthuis M, Albers HF, van Jeveren JG, Wil de Jong J, Hautvast JG, Hermus RJ, Katan MB, Brydon WG \& Eastwood MA (1980) Influence of dietary fiber from vegetables and fruits, bran or citrus pectin on serum lipids, fecal lipids, and colonic function. Am J Clin Nutr 33, $1745-1756$.

Steffen LM, Jacobs DR Jr, Stevens J, Shahar E, Carithers T \& Folsom AR (2003) Associations of whole-grain, refined-grain, and fruit and vegetable consumption with risks of all-cause mortality and incident coronary artery disease and ischemic stroke: the Atherosclerosis Risk in Communities (ARIC) Study. Am J Clin Nutr 78, 383-390.

Thompson FE, Subar AF, Smith AF, Midthune D, Radimer KL, Kahle LL \& Kipnis V (2002) Fruit and vegetable assessment: performance of 2 new short instruments and a food frequency questionnaire. J Am Diet Assoc 102, 1764-1772.

Tinker LF, Schneeman BO, Davis PA, Gallaher DD \& Waggoner CR (1991) Consumption of prunes as a source of dietary fiber in men with mild hypercholesterolemia. Am J Clin Nutr 53, $1259-1265$.

Tunstall-Pedoe H, Kuulasmaa K, Mahonen M, Tolonen H, Ruokokoski E \& Amouyel P (1999) Contribution of trends in survival and coronary-event rates to changes in coronary heart disease mortality: 10-year results from 37 WHO MONICA project populations. Monitoring trends and determinants in cardiovascular disease. Lancet 353, $1547-1557$.

Wisker E, Schweizer TF, Daniel M \& Feldheim W (1994) Fibremediated physiological effects of raw and processed carrots in humans. Br J Nutr 72, 579-599.

Yarnell JW (1998) The PRIME study: classical risk factors do not explain the severalfold differences in risk of coronary heart disease between France and Northern Ireland. Prospective Epidemiological Study of Myocardial Infarction. QJM 91, 667-676.

Zino S, Skeaff M, Williams S \& Mann J (1997) Randomised controlled trial of effect of fruit and vegetable consumption on plasma concentrations of lipids and antioxidants. BMJ 314, $1787-1791$. 